\title{
Baby Check: a scoring system to grade the severity of acute systemic illness in babies under 6 months old
}

\author{
C J Morley, A J Thornton, T J Cole, P H Hewson, M A Fowler
}

\begin{abstract}
A scoring system has been developed to grade the severity of acute systemic illness in babies under 6 months of age. Data were collected on 28 symptoms and 47 signs from 1007 babies with a spectrum of illness ranging from well to seriously ill. Ordinal regression analysis identified 19 symptoms and signs which in combination graded the severity of the illness most accurately. The coefficients were converted to scores. The higher the score the more serious the illness. When applied to a theoretical cohort of $\mathbf{1 0} 000$ babies at home, a score less than 8 has a specificity of $98 \%$, and a score of 13 or more a sensitivity of $92 \%$. The positive predictive value for serious illness increases from zero at a score of zero to approaching $100 \%$ at scores over 30 . The scoring system has been developed into score cards for parents and professionals.
\end{abstract}

Parents and doctors recognise when babies are unwell, but they sometimes find it hard to gauge the severity of the illness. Early recognition of serious illness in babies might reduce morbidity and mortality. ${ }^{12}$ However, there is little information about which are the important signs and symptoms people should be taught to recognise. The preliminary report of the Department of Health and Social Security study of postneonatal mortality suggested 12 symptoms that warranted medical attention the same day. ${ }^{3}$ Unfortunately, most were considered to be too common in the community to be useful predictors of serious illness. ${ }^{4-7}$ Valman subsequently suggested four 'undoubtedly sinister' symptoms that warranted a paediatric opinion. ${ }^{8}$

University of Cambridge, Department of Paediatrics C J Morley A J Thornton M A Fowler

MRC Dunn

Nutrition Unit, Cambridge T J Cole

Department of Paediatrics, Royal Children's Hospital,

Melbourne,

Australia

P H Hewson

Correspondence to:

Dr C J Morley,

University of Cambridge,

Department of Paediatrics,

Levartmen,

Level E8,
Addenbrooke's Hospital,
Hills Road,

Cambridge CB2 2QQ.

Accepted 10 August 1990 least two were 'too common in infants at home to be regarded as truly sinister'. 9 Valman said that 'the incidence of sinister symptoms in the community needs to be assessed and objective methods of assessing serious illness taught'. A recent House of Commons report reinforced this view. ${ }^{10}$

In companion papers we have presented information about individual symptoms and signs in babies under 6 months old. ${ }^{11} 12$ They show that many symptoms and signs in seriously ill babies also occur in babies who are mildly ill. A few individual symptoms and signs are seen only in seriously ill babies but these are rare and indicate an advanced stage of illness. Their sole use would mean that many babies would be missed. Furthermore, it would be preferable to recognise that a baby is ill before he exhibits such signs. If less specific symptoms and signs are used to identify seriously ill babies this will increase anxiety and the workload of the family doctor. This paper presents a scoring system that uses a combination of symptoms and signs to grade the severity of acute systemic illness in babies under 6 months old. The study design and details of the statistical analysis have been reported elsewhere. ${ }^{13}$

\section{Methods}

NUMBERS OF BABIES REQUIRED FOR THE STUDY Accurate determination of the symptoms and signs associated with serious illness requires the rarest to be recorded at least five times. ${ }^{14} \mathrm{~A}$ study in the community would need to enrol about 30000 babies to ensure this. The only practical way to collected data from seriously ill babies was to enrol them when they presented to hospital, where the incidence of serious illness is much higher than at home. At least 600 were needed to ensure that the rarest symptoms and signs were recorded at least five times. At home, 300 babies were sufficient to quantify the incidence of all but the rarest symptoms and signs.

\section{ENROLMENT OF BABIES}

During one year 298 randomly selected full term babies were enrolled postnatally in Cambridge and seen at home evenly across postnatal age (1-25 weeks) and seasons. During the same period 709 babies under 26 weeks old presenting to hospital with an acute problem were enrolled: 27 in Cambridge and 682 at the Royal Children's Hospital, Melbourne (RCH). The $\mathrm{RCH}$ assesses a large number of babies with a wide variety of problems because it acts as a primary care centre for the local population.
THE ASSESSMENT

Each mother was asked about 28 predefined symptoms, ${ }^{11}$ their duration and her impression of the severity. Only symptoms present in the preceding 24 hours were recorded. Some were clarified with additional questions. The baby was then examined for 47 physical signs. ${ }^{12} 15$ The two observers (AJT and PHH) used an identical history questionnaire and examination procedure and practised the assessment to minimise interobserver error. At the end of the study they compared notes to look for systematic differences. As a result two signs, mottling of the skin and mucousy breathing, were found to have been assessed differently and were excluded from further analyses. 
GRADING THE SEVERITY OF ILLNESS

The aim of this study was to grade systemic illness. As there is no 'gold standard' for this it was graded subjectively by the assessors into well, mildly ill, moderately ill, or seriously ill. For comparison each baby's illness was also graded, where possible, using other criteria: positive investigation results $(n=200)$, a review of the notes by three independent paediatricians $(n=248)$, and investigation results $(n=682)$. All the babies were also followed up for three days to ensure no serious diseases had been missed. After comparing each of these criteria, the assessor's impression of the illness was chosen as the grading for subsequent analyses because it was recorded for all babies at the time they were seen, and there was a high level of concordance between this and the independent paediatrician's review $(x=0.62, p<0.001) .1617$ This level of agreement is similar to other studies comparing clinical judgment. ${ }^{18} 19$

\section{EXPLORATORY ANALYSES}

Details of the statistical analysis of this study are reported in full elsewhere. ${ }^{13}$ Exploratory analyses showed that symptoms best discriminated illness severity if they were present only during the preceding three days. Continuous variables were investigated as linear and quadratic trends. Most, including respiratory rate, pulse rate, weight, and weight change did not contribute to the prediction of illness severity in the presence of other variables. Two exceptions were rectal temperature and vomiting. These were converted to present/absent variables using the cut offs $>38.2^{\circ} \mathrm{C}$ and 'vomits of at least half the feed after each of the last three feeds'.

\section{IDENTIFICATION OF THE BEST COMBINATION OF} SYMPTOMS AND SIGNS FOR GRADING ILLNESS Logistic and ordinal regression analyses were used to identify the best combination of symptoms and signs to differentiate the three illness groups (well plus mildly ill, moderately ill, and seriously ill). ${ }^{20} 21$ The regression coefficient for each symptom and sign represents the increased chance of a baby being ill when that symptom or sign is present. Thus compared with an asymptomatic baby, the chance of a symptomatic baby being ill is the sum of the coefficients for the symptoms which are present. The regression coefficients were converted to integers by multiplying by 3.93 to make a manageable score. ${ }^{22}$ The total score could then be calculated for each baby by identifying which of the 19 symptoms and signs the baby had, and adding the corresponding scores.

\section{THE SCORES IN A THEORETICAL COMMUNITY} POPULATION

The sample was weighted towards hospital babies. To find the scores likely to occur in the community, a theoretical cohort of 10000 babies was calculated by taking the babies seen at home as $\mathbf{9 8 \%}$ of the population and those seen in hospital as $2 \%$. These proportions were based on the assumption that the hospital babies represented the illest $2 \%$ of the population.

\section{SENSITIVITY, SPECIFICITY, AND PREDICTIVE} VALUES

The scoring system is designed to grade the severity of a baby's illness, with increasing scores identifying sicker babies. Specificity (the accuracy with which the score identifies well or mildly ill babies) and sensitivity (the accuracy with which the score identifies seriously ill babies) are calculated for groups of scores as an illustration of the accuracy of the scoring system. Predictive values (the chance of a baby with a given score having a given grade of illness) are shown for individual scores.

\section{Results}

Of the 1007 babies, 298 were seen at home and 709 in hospital, of whom 180 were admitted and 529 sent home; two admitted babies died. The assessors' impressions of the babies' illnesses were: 290 well, 305 mildly ill, 247 moderately ill, and 165 seriously ill, of whom nine needed resuscitation.

Of the babies at home $290 / 298(97 \%)$ were well or mildly ill. None was considered to be seriously ill (table 1). Of the babies presented to hospital 165/709 (23\%) were seriously ill, 239/ 709 (34\%) moderately ill, and 305/709 (43\%) well or mildly ill. They had a wide range of conditions-for example, upper respiratory tract infection $(n=81)$, lower respiratory tract problems $(n=135)$, diarrhoea and vomiting $(n=$ $64)$, feeding problems $(n=20)$, apnoea $(n=16)$, colic $(n=27)$, intussusception $(n=11)$, meningitis $(n=10)$, urinary infections $(n=16)$, and eczema and dermatitis $(n=92)$.

\section{THE SCORE CARD}

Table 2 shows the seven symptoms and 12 signs that in combination graded illness severity best. They are presented as the elements of the score card, called Baby Check, for use by doctors and nurses. The complete version includes definitions, instructions, caveats, and information about interpretation of the score. A booklet for parents has also been produced using identical symptoms, signs, and scores but with more

Table 1 Numbers of babies in each illness category by score group and location

\begin{tabular}{|c|c|c|c|c|c|}
\hline & \multicolumn{5}{|c|}{ Score groups } \\
\hline & $\overline{0-7}$ & $8-12$ & $13-19$ & $20+$ & All \\
\hline $\begin{array}{l}\text { Babies seen at home } \\
\text { Well or mildly ill } \\
\text { Moderately ill } \\
\text { Seriously ill }\end{array}$ & $\begin{array}{r}286 \\
3 \\
0\end{array}$ & $\begin{array}{l}3 \\
3 \\
0\end{array}$ & $\begin{array}{l}1 \\
2 \\
0\end{array}$ & $\begin{array}{l}0 \\
0 \\
0\end{array}$ & $\begin{array}{r}290 \\
8 \\
0\end{array}$ \\
\hline Total & 289 & 6 & 3 & $\mathbf{0}$ & 298 \\
\hline $\begin{array}{l}\text { Babies seen in hospi } \\
\text { Well or mildly ill } \\
\text { Moderately ill } \\
\text { Seriously ill }\end{array}$ & $\begin{array}{r}\text { ital: } \\
189 \\
47 \\
8\end{array}$ & $\begin{array}{r}77 \\
67 \\
5\end{array}$ & $\begin{array}{l}36 \\
77 \\
26\end{array}$ & $\begin{array}{r}3 \\
48 \\
126\end{array}$ & $\begin{array}{l}305 \\
239 \\
165\end{array}$ \\
\hline Total & 244 & 149 & 139 & 177 & 709 \\
\hline $\begin{array}{l}\text { Theoretical cohort of } \\
\text { home:hospital: } \\
\text { Well or mildly ill } \\
\text { Moderately ill } \\
\text { Seriously ill }\end{array}$ & $\begin{array}{r}1000 \\
9459 \\
112 \\
2\end{array}$ & $\begin{array}{r}120 \\
118 \\
1\end{array}$ & $\begin{array}{r}43 \\
87 \\
7\end{array}$ & $\begin{array}{r}1 \\
14 \\
36\end{array}$ & $\begin{array}{r}9623 \\
331 \\
46\end{array}$ \\
\hline Total & 9573 & 239 & 137 & 51 & 10000 \\
\hline
\end{tabular}


Table 2 The Baby Check score card. The combination of symptoms and signs shown by regression analysis to predict most significantly the severity of illness

Score palue

Score each item according to the exact wording of the question. Only score if an item is definitely present. The baby can be rescored at any time to assess changes in severity of the illness

Ask about the presence of these symptoms in the last 24 hours:

(1) Has the baby vomited at least half the feed after each of the last three feeds?

(2) Has the baby had any bile stained (green) vomiting?

(3) Has the baby taken less fluids than usual in the last 24 hours?

If so, score for the total amount of fluids taken as follows:

Taken only slightly less than usual (more than two thirds of usual intake)

Taken about half the usual amount (between one third and two thirds of usual intake)

Taken very little (less than one third of usual intake)

- If breast fed ask mother to estimate the amount taken

- Fluids that have been vomited should still be scored

(4) Has the baby passed less urine than usual?

(5) Has there been any frank blood mixed with the baby's stools?

Has there been any frank

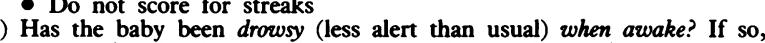
score for the degree of drowsiness when awake, as follows:

Occasionally drowsy (but usually alert)

Drowsy most of the time (occasionally alert)

Drowsy all the time (never alert)

- Ensure that mother is reporting drowsiness and not just irritability or increased sleeping

(7) Has the baby had an unusual cry (sounds unusual to mother)?

Now examine the baby awake:

(8) Is the baby's muscle tone reduced?

- Compare tone and head control to normal for baby's age

(9) Talk to the baby. Is the baby concentrating on you less than you would expect?

(10) Is the baby wheezing on expiration?

- Do not score for snuffles or upper respiratory noises

(11) Is the baby responding to what is going on less than you would expect?

$\begin{aligned} 4 & <0.001 \\ 13 & <0.01 \\ 3 & <0.001 \\ 4 & <0.0001 \\ 9 & <0.0001 \\ 3 & <0.01 \\ 11 & <0.001 \\ & \\ 3 & <0.01 \\ 5 & <0.001 \\ 5 & <0.001 \\ 2 & <0.01 \\ 4 & <0.0001 \\ 4 & <0.05 \\ 4 & <0.05 \\ 3 & <0.05 \\ 5 & \end{aligned}$

Now undress the baby and examine the baby naked:

(12) Is there any indrawing (recession) of the lower ribs, sternum or upper abdomen? If so, scores as follows:

Mild recession (slight indrawing, just visible)?
Moderate recession (obvious indrawing, clearly visible)?

Moderate recession (obvious indrawi
Severe recession (deep indrawing)?

(13) Is the baby very pale or does the parent think that the baby has looked very pale in the last 24 hours (ask the parent)?

(14) Is the baby peripherally cyanosed?

(15) Squeeze the baby's big toe firmly for 2 seconds to make it white. Release and observe colour return for 3 seconds. Score if return is not complete within 3 seconds, or if toe was completely white to start with

(16) Has the baby got an inguinal hernia?

- $60 \%$ of babies with an inguinal hernia develop complications

(17) Has the baby an obvious generalised truncal rash or a raw or weeping rash covering an area greater than $5 \mathrm{~cm} \times 5 \mathrm{~cm}$ ?

(18) Is the baby's rectal temperature $38.3^{\circ} \mathrm{C}$ or more?

(19) Has the baby cried during this assessment (more than just a grizzle)?

Total score

PREDICTIVE VALUES OF THE SCORES

Table 3 shows the predictive values of a baby having each grade of illness at different scores. The values were derived from curves fitted to the data. The predictive value for serious illness increases from near zero at low scores to nearly $100 \%$ for scores over 30 . The predictive value for moderate illness is low at low scores, rising to a peak at a score of 16 and falling to zero at high scores. For babies scoring over 16, the chance of having a moderate or serious illness is at least $80 \%$. The risk of serious illness rises steeply for scores over 10 . The higher the score the greater the chance of a serious illness.

\section{SCORE GROUPS}

The specificity and sensitivity of different score cut offs were explored using Receiver Operating Characteristic curves. Scores of 8 and 13 were identified as the most appropriate lower limits to define moderate and serious illness respectively. A score of 20 defines a group at very high risk of serious illness. The score groups are
Table 3 The predictive values of a baby being well or mildly ill, moderately ill, or seriously ill at different scores

\begin{tabular}{cccc}
\hline Score & $\begin{array}{l}\text { Well or mildly ill } \\
(\%)\end{array}$ & $\begin{array}{l}\text { Moderately ill } \\
(\%)\end{array}$ & $\begin{array}{c}\text { Seriously ill } \\
(\%)\end{array}$ \\
\hline 0 & 99 & 1 & 0 \\
2 & 90 & 9 & 1 \\
4 & 85 & 14 & 1 \\
6 & 77 & 21 & 2 \\
8 & 66 & 30 & 4 \\
10 & 54 & 41 & 5 \\
12 & 41 & 51 & 8 \\
14 & 30 & 58 & 12 \\
16 & 20 & 62 & 18 \\
18 & 13 & 62 & 25 \\
20 & 8 & 58 & 34 \\
22 & 5 & 50 & 45 \\
24 & 3 & 41 & 56 \\
26 & 2 & 32 & 66 \\
28 & 1 & 24 & 75 \\
30 & 0 & 17 & 83 \\
32 & 0 & 12 & 88 \\
34 & 0 & 8 & 92 \\
36 & 0 & 5 & 95 \\
38 & 0 & 3 & 97 \\
40 & 0 & 2 & 98 \\
42 & 0 & 1 & 99 \\
44 & 0 & 1 & 99 \\
46 & 0 & 0 & 100 \\
48 & 0 &
\end{tabular}

The three grades of illness are defined as: well or milldly ill = unlikely to need medical attention at present; moderately be watched closely and probably reviewed; and seriously ill =need

The table can be used to assess the chance of a baby with a The table can be used to assess the chance of a baby with given score having each grade of illness. For example, a baby with a score of 24 would have a $3 \%$ chance of being well or mildly being seriously ill. 
interpreted for parents as: score 0 to $7:$ 'Your baby is well or only a little unwell and is not likely to need medical attention at the moment.' Score 8 to 12: 'Your baby is unwell, but is not likely to be seriously ill. Contact your doctor, health visitor or midwife for advice. Watch your baby closely, if you think your baby is getting worse do the score again'. Score 13 to 19: 'Your baby is ill and needs to be seen by a doctor. Contact your doctor now and arrange for your baby to be seen'. Score 20 or more: 'Your baby may be seriously ill and needs to be seen by a doctor straight away'. Parents are advised to repeat the score if they think the baby is getting worse.

DISTRIBUTION OF SCORES BY ILLNESS GRADE, LOCATION, AND DIAGNOSIS

Table 4 shows the score centiles for the grades of illness for babies seen at home and in hospital, for babies admitted and sent home, and some common diagnoses.

SCORES FOR BABIES AT HOME

Of the 298 babies seen at home, six (2\%) scored between 8 and 12 and three (1\%) scored 13 or more, the highest 16 . Thus if the mothers had scored the babies at the time, $2 \%$ would have been encouraged to get non-urgent medical advice and $1 \%$ urgent advice (table 1 ). If the scoring system were used widely in the community a score of 20 or more would occur in 51/ $10000(0.5 \%)$ babies, of whom 36/51 (71\%) would be considered seriously ill and 14/51 (27\%) moderately ill; only $1 / 51$ (2\%) would be well or mildly ill.

SCORES FOR BABIES IN HOSPITAL

One hundred and forty four $(80 \%)$ of the babies admitted to hospital scored 13 or more. All the babies with life threatening illnesses such as meningitis or intussusception scored over 20 . Table 4 shows the median, 10th, and 90th centiles of the score for some common diagnoses.

Table 4 Distribution of scores for babies with different grades of illness, in different locations, and for several diagnoses

\begin{tabular}{|c|c|c|c|c|}
\hline & \multirow[t]{2}{*}{$\begin{array}{l}\text { No of } \\
\text { babies }\end{array}$} & \multicolumn{3}{|c|}{$\begin{array}{l}\text { Centiles for the } \\
\text { scores }\end{array}$} \\
\hline & & 10 & 50 & 90 \\
\hline $\begin{array}{l}\text { Grade of illness: } \\
\text { Well } \\
\text { Mildly ill } \\
\text { Moderately ill } \\
\text { Seriously ill }\end{array}$ & $\begin{array}{l}290 \\
305 \\
247 \\
165\end{array}$ & $\begin{array}{r}0 \\
0 \\
6 \\
13\end{array}$ & $\begin{array}{r}0 \\
6 \\
13 \\
29\end{array}$ & $\begin{array}{r}6 \\
13 \\
23 \\
41\end{array}$ \\
\hline $\begin{array}{l}\text { Location: } \\
\text { Seen at home } \\
\text { Seen in hospital } \\
\text { Hospital sent home } \\
\text { Hospital admitted }\end{array}$ & $\begin{array}{l}298 \\
709 \\
529 \\
180\end{array}$ & $\begin{array}{l}0 \\
3 \\
3 \\
7\end{array}$ & $\begin{array}{r}0 \\
11 \\
9 \\
25\end{array}$ & $\begin{array}{r}5 \\
30 \\
20 \\
41\end{array}$ \\
\hline $\begin{array}{l}\text { Diagnosis: } \\
\text { Conjunctivitis } \\
\text { Upper respiratory tract infection } \\
\text { Lower respiratory tract infection } \\
\text { Diarrhoea and vomiting } \\
\text { Hernia } \\
\text { Bronchiolitis } \\
\text { Intussusception } \\
\text { Meningitis }\end{array}$ & $\begin{array}{l}18 \\
81 \\
74 \\
64 \\
12 \\
51 \\
11 \\
10\end{array}$ & $\begin{array}{r}0 \\
3 \\
4 \\
4 \\
11 \\
11 \\
21 \\
20\end{array}$ & $\begin{array}{r}4 \\
8 \\
13 \\
13 \\
24 \\
25 \\
31 \\
32\end{array}$ & $\begin{array}{r}8 \\
20 \\
24 \\
30 \\
34 \\
41 \\
51 \\
44\end{array}$ \\
\hline
\end{tabular}

SPECIFICITY AND SENSITIVITY

Table 1 shows the number of babies with each grade of illness with scores in the ranges 0-7, $8-12,13-19$, and 20 and above at home, in hospital, and in a theoretical community population of 10000 babies.

The specificity of a score between 0 and 7 to identify well or mildly ill babies was lower in babies seen in hospital $(189 / 305,62 \%)$ than at home $(286 / 290,99 \%)$. The specificity for the theoretical community cohort was $9459 / 9623$ (98\%). Thus the false positive rate for well or mild illness when used in the community would be about $2 \%$.

The sensitivity of a score of 13 or more to detect a seriously ill baby was $152 / 165$ (92\%), giving a false negative rate of $8 \%$. The sensitivity was unchanged for the theoretical community cohort, $43 / 46$ (93\%).

\section{FALSE NEGATIVE SCORES}

The $8 / 165(5 \%)$ babies considered to be seriously ill who had scores of less than 8 had diagnoses of gastro-oesophageal reflux $(n=3)$, and one case each of unusual head nodding, convulsion, severe skin rash, early osteomyelitis, and a fractured skull. A further $5 / 165(3 \%)$ graded as seriously ill had scores between 8 and 12. Their diagnoses were enterovirus infection, renal abnormality, screaming (no diagnosis found), acyanotic heart disease (not in heart failure), and a fractured arm. All these babies either had an obvious problem that needed medical attention, or were not seriously ill.

In the community only $2 / 9573(0 \cdot 02 \%)$ babies with low scores ( 0 to 7$)$ would be considered to be seriously ill.

\section{FALSE POSITIVE SCORES}

Three babies assessed as well scored 13, 13, and 17 , and 37 babies rated as mildly ill scored 13 or more (five scored more than 17). Review of the case histories and diagnoses suggested that the scores gave a reasonable impression of each baby's illness - that is, they needed to be assessed by a doctor.

\section{MOTHERS' IMPRESSION OF THE ILLNESS} COMPARED WITH THE SCORE

For babies seen in hospital the mother's grading of the baby's illness was compared with that of the assessor. The mothers graded 474/709 (67\%) babies as moderately or severely ill compared with $404 / 709$ (57\%) graded as such by the assessor. The concordance was poor $(x=0 \cdot 26)$. The mothers' grading of moderate or serious illness had a positive predictive value of $66 \%$ and a negative predictive value of $62 \%$. The scoring system using a cut off of 13 or more gave a positive predictive value of $88 \%$ and a negative predictive value of $68 \%$. The score was therefore more accurate at grading illness than the mothers.

\section{Discussion}

Paediatricians use their clinical judgment to sift 
rapidly through many symptoms and signs to assess whether a baby is seriously ill. The scoring system presented in this paper has distilled the 19 factors that in combination can simulate the assessment of one experienced paediatrician (PHH). It is therefore a systematised version of his personal judgment. There was reasonable concordance between $\mathrm{PHH}$ and the independent paediatricians, suggesting that the 19 items also reflect their judgment. The significance levels of the 19 symptoms and signs shown in table 2 suggest that if the study were repeated most of the factors would still be identified as important. Use of the score card should enable parents and family doctors to give a grade to the illness severity similar to that of the original paediatrician.

The study data came from two centres, each with its own observer and prevalence of illness. This may have affected the 19 symptoms and signs identified. However, this difficulty has been considered during the analysis. In addition to the results presented in the combined data, separate analyses were carried out on the Melbourne data alone to remove the interobserver effect. The results were very similar, with the same combination of symptoms and signs being identified, although there were differences in the values of the scores, reflecting the inclusion of a large number of well babies in the combined data set. The similarity of the results suggests that illness severity rather than any difference between the two observers or centres was the reason the individual symptoms and signs were selected.

Although the prevalence of disease in the two centres was different, the signs and symptoms associated with specific conditions such as bronchiolitis were the same. Thus the combination of symptoms and signs should be useful for grading illness anywhere.

A scoring system to be used by inexperienced people must not miss serious illness. The $8 \%$ false negatives either had conditions that would not have been considered serious by other observers, or would have been recognised from other features (for example, a swollen immobile arm in the case of osteomyelitis).

The score assesses the severity of acute systemic illness. Some conditions, such as a convulsion, obviously need medical attention but may get a low score if the baby is not systemically ill. In most cases a score is not needed to assess such conditions. If there is any doubt, however, the score can still be used to show the level of systemic illness. For example, a baby with a fit may score 0 if generally well, or 30 if it has meningitis. The score card includes specific information about conditions which need medical care but which score low. The scoring system is not a substitute for common sense or experience, rather it is a tool to help people quantify the severity of an illness.

The score grades the illness at the time it is done and can be repeated to assess whether the baby is getting better or worse.

If the scoring system were to be used at home it would probably not increase the number of mothers seeking medical attention. In this study it would have encouraged $1 \%$ to seek urgent attention and $2 \%$ non-urgent advice. In fact $3 \%$ had seen the doctor on the day of the assessment and two babies were under review. ${ }^{11}$ An unrecorded number had also seen the midwife or health visitor. Babies at home who scored less than 8 were very likely to be considered well or mildly ill. Thus the score card should give mothers confidence not to seek medical advice. It could also encourage them to seek urgent medical advice appropriately if their baby had a high score.

Some symptoms and signs that might be considered important were not selected for the score card. This was because either they were very uncommon, or other factors in combination were better at differentiating the illness, or their addition did not significantly improve the accuracy of the score.

Some people might be unhappy about mothers measuring rectal temperature. A digital thermometer is provided with the mother's score card. It has a rounded end $3 \mathrm{~mm}$ in diameter and a flange to prevent insertion too far into the rectum. Illustrations show how it should be used. Our experience, and that of others, ${ }^{23}$ is that mothers can safely measure rectal temperature.

This scoring system is the most accurate system for grading acute systemic illness we could devise. Although it would be desirable to have a simple check list of a few individual symptoms and signs ${ }^{15}$ it would not grade the illnesses as accurately, nor be so sensitive or specific as the Baby Check system, which uses a weighted combination of symptoms and signs.

It is important to find out how the score card works in practice, whether or not people can use it and find it useful, and how accurate it is in different situations. These issues have been studied in field trials, the results of which are reported in companion papers. ${ }^{24-27}$

In conclusion, the Baby Check scoring system using a combination of 19 symptoms and signs appears to be a highly sensitive and specific tool which should be useful to help quantify the severity of a baby's systemic illness.

We thank the Baby Illness Research Project Appeal of the Foundation for the Study of Infant Deaths, the Australian Institute of Health, the Ross Trust, Felton Bequests, the $\mathrm{H} \mathrm{L}$ Hecht Trust, the Percy Baxter Charitable Trust, and the A Williams Private Fund. Drs D Roberton, I McNamara, and $M$ Robinson reviewed the Melbourne case notes. S Humphries, S Bechervaise, C Hewson (Melbourne), and J Tunnacliffe (Cambridge) followed up the babies and kept the records.

Copies of the Baby Check score card and booklet can be obtained from the authors.

1 McWeeny PM, Emery JL. Unexpected postneonatal deaths (cot deaths) due to recognisable disease. Arch Dis Child 1975;50:191-6.

2 Oakley JR, McWeeny PM, Hayes-Allen M, Emery JL. Possibly avoidable deaths in hospital in the age-group one week to two years. Lancet 1976; i:770-2.

3 Stanton AN, Downham MAPS, Oakley JR, Emery JL, Knowelden J. Terminal symptoms in children dying suddenly and unexpectedly at home: preliminary report of the DHSS multicentre study of post neonatal mortality. $B M \mathcal{Y}$ 1978;ii:1249-51.

4 Grabinar D. Terminal symptoms in children dying suddenly and unexpectedly. $B M \mathcal{F}$ 1978;ii: 1430 .

5 Valentine $S$. Terminal symptoms in children dying suddenly alentine S. Terminal symptoms in child

6 Struthers J. Terminal symptoms in children dying suddenly and unexpectedly. $B M \mathcal{F}$ 1978; ii: 1430 .

7 Greaves D, Boddy A. Terminal symptoms in children dyin suddenly and unexpectedly. $B M \mathcal{J}$ 1978;ii:1495-6.

Valman B. Preventing infant deaths. $B M \mathcal{J}$ 1985;290:339-40.

9 Thurtle OA, Cox P, Fall C, et al. Preventing infant deaths. $B M \mathcal{F}$ 1985;290:1434-5. 
10 House of Commons Social Services Committee First Report. Perinatal, neonatal and infant mortality. London: HMSO, 1988.

11 Thornton AJ, Morley CJ, Hewson PH, Cole TJ, Fowler MA, Tunnacliffe JM. Symptoms in 298 infants under six months old, seen at home. Arch Dis Child 1990;65:280-5.

12 Morley CJ, Thornton AJ, Cole TJ. Symptoms and signs in babies under six months old correlated with the severity of babies under six months old correla
their illness. Pediatrics (in press).

13 Cole TJ, Morley CJ, Thornton AJ, Fowler MA, Hewson PH A scoring system to quantify illness in babies under six A scoring system to quantify illness in babies under six
months of age. Fournal of the Royal Statistical Society $A$ (in

14 Wasson

asson JH, Sox HC, Neff RK, Goldman L. Clinical prediction rules. Applications and methodological standards. $N$ Engl f Med 1985;313:793-9.

15 Hewson PH, Humphries SM, Roberton DM, McNamara JM, Robinson MJ. Markers of serious illness in infants under 6 months old presenting to a children's hospital. Arch Dis Child 1990;65:750-6.

16 Kramer MS, Feinstein AR. Clinical biostatistics LIV. The biostatistics of concordance. Clin Pharmacol Ther 1981;29:111-23

17 Landis JR, Koch GG. The measurement of observer agreement for categorical data. Biometrics 1977;33:159-74.

18 Spiteri MA, Cook DG, Clarke SW. Reliability of eliciting physical signs in examination of the chest. Lancet 1988;i:873-5.
19 Garraway WM, Akhtar AJ, Gore SM, Prescott RJ, Smith RG. Observer variation in the clinical assessment of stroke.

Age Ageing 1979;5:233-40.
20 McCullagh P. Regression models for ordinal data (with discussion). Fournal of the Royal Statistical Society $B$ 1980;42:109-42.

21 Cole TJ, Lane PW. ORDINALLOGISTIC. In: Payne RW, Arnold GM, eds. Genstat 5 procedure library manual release Arnold GM, eds. Genstat 5 procedure library manual

22 Cole TJ. Scaling and rounding regression coefficients to integers. Appl Statistics (in press)

23 Ipp MM, Gold R, Greenberg S, et al. Acetaminophen prophylaxis of adverse reactions following vaccination of infants with diphtheria-pertussis-tetanus toxoids-polio vaccine. Pediatr Infect Dis $\mathcal{f}$ 1987;6:721-5.

24 Thornton AJ, Morley CJ, Green SJ, Cole TJ, Walker KA Bonnett JM. Field trials of the Baby Check score card mothers scoring their babies at home. Arch Dis Child 1991;66:106-10.

25 Thornton AJ, Morley CJ, Cole TJ, Green SJ, Walker KA Rennie JM. Field trials of the Baby Check score card in hospital. Arch Dis Child 1991;66:115-20.

26 Morley CJ, Thornton AJ, Green SJ, Cole TJ. Field trials of the Baby Check score card in general practice. Arch Dis Child 1991;66:111-4.

27 Cole TJ, Thornton AJ, Green SJ, Morley CJ. Field trials of Baby Check: a scoring system to quantify illness in babies under six months. Medical Informatics 1990 (in press).

\section{NOWCA}

Some small babies get into alarming difficulty with nasal obstruction or snuffliness. Reference to standard paediatric texts for guidance on the management of this problem is singularly unhelpful. Perhaps the first step is to have a name for the problem so that we can recognise it and talk about it. Derkay and Grundfast in a welcome paper (International fournal of Pediatric Otorhinolaryngology 1990;19:241-9) call it NOWCA (nasal obstruction without choanal atresia). They describe 15 babies aged between 1 week and 8 months seen in Washington DC. Methods of assessment included fibreoptic and rigid tube endoscopy, computed tomography of the nose, and sleep studies with measurement of heart rate, chest wall movement, nasal or tracheal air flow, and oxygen saturation by pulse oximetry. Of the 15 babies four had oedema of the nasal mucosa, three each had isolated choanal stenosis, choanal stenosis with other craniofacial anomalies, and adenoid obstruction, and two had congenital syphilis.

Therapeutic measures included insertion of a nasopharyngeal airway, steroid nose drops, adenoidectomy, and home cardiorespiratory monitoring after teaching parents about resuscitation. Twelve of the babies were well by 6 months of age and the other three by 9 months.

I suspect that this is a fairly common problem that we've been slow to latch on to, though I don't expect to see many caused by congenital syphilis. The next time you see your friendly ear, nose, and throat surgeon say 'NOWCA' and if he doesn't respond hit him about the head with this paper. 